\title{
INTERNATIONAL ORGANIZATION AND SUCCESSFUL MARKETING IN ALBANIAN STAKEHOLDERS
}

\section{Dr. GERTI DAJCI}

Tirana Business University College, Tirana Albania

\begin{abstract}
The key element for a successful organization is to do internal marketing; that is, to gain the support of the stakeholders and the visionary leaders who support the need to implement it. Implementing thoughtful remedies to put in place to overcome these stakeholder barriers and resistance are the opposite forces facing their resistance. Key leaders must empower their stakeholders and generating consensus. To accomplish this, leaders need to embrace their core basic values and beliefs of honesty, reliability, fairness, self-discipline, and develop responsible management practices to meet reasonable stakeholder expectations. The organizations must provide training and learning to empower their employees toward the desired direction, either technical, financial, political, etc. This paper explores, identifies, and assesses an implementation plan for many international organizations. This paper combines relevant literature research that is relevant to the implementation plan, and discusses issues, solutions, execution of the solutions, and evaluation of the implementation plan.
\end{abstract}

\section{Implementation Plan and Organizational Structure}

Key supporting factors of how you implement the strategic plan defines the success of your company. Those organizations that are successful at implementing strategy give thought to the organizational structure. They ask if their intended strategy fits their current structure. And 
ISSN 2661-264X (Print)

they ask a deeper question as well... "Is the organization's current structure appropriate to the intended strategy?" (Birnbaum, 2011). Organizations successful at strategy implementation consider the human resource factor in making strategies happen. Consideration of human resources requires that management think about the organization's communication needs. That they articulate the strategies so that those charged with developing the corresponding action steps (tactics) fully understand the strategy they're to implement (Birnbaum, 2011). After further review of implementing strategic plan, organizations should take different opportunities for planning process, which will help with implementation of your strategies in later years.

The researcher introduces an organizational structure based on the leadership. Starts with the CEO and ends with the managers of particular departments. Each of the leaders is responsible for their department and the assigned tasks to their employees. A great leader can take a group and accomplish what was impossible to many people. In order to accomplish the goals, they must make incremental changes that are challenging, but not impossible. A leader should give to organization a string of successes, which builds momentum and attitudes that helps to overcome difficult situations in the future.

\section{Monitoring, control, and follow-up mechanisms}

The key element for a successful organization is to do internal marketing; that is, to gain the support of the stakeholders and the visionary leaders who support the need to implement it. Implementing thoughtful remedies to put in place to overcome these stakeholder barriers and resistance are the opposite forces facing their resistance. For example, if they fear losing their job, the organization must assure them that if they do not change course and adapt to the new direction, there will be no job to keep. Key leaders must empower their stakeholders and generating consensus. To accomplish this, leaders embracing their core basic values and beliefs of honesty, reliability, fairness, self-discipline, and develop responsible management practices to meet reasonable stakeholder expectations. The organization must provide training and learning to empower their employees toward the desired direction, either technical, financial, political, etc. In addition, there should be measurement systems and surveys in order to track the effects of change. Change management implementation throughout the organization for effective follow-through mechanisms, such as the principles of continuous improvement. The ability to build local and international relationships, enable the gathering of current data from all levels of the organization, and remain current with external social and environmental changes significantly add to developing and steering strategy implementation. 


\section{Time Frame}

Increased awareness of the impact individuals and organizations have on the community, economy, and the environment has created a demand for socially and environmentally sustainable products and services in many industries.

To have a better understanding of the success of the strategic plan, the researcher will create preliminary 1-2 years timeline projects development as a business strategy.

\section{Solutions Focused Learning (SFL)}

To have a better understanding of the implementation plan, the researcher will use Solutions Focused Learning (SFL) method as a part of the strategy. Solutions Focused Learning (SFL) is a learning method, which may be used frequently in the fields of counseling and education along in the field of management (Metcalf, 2008). The researcher by diagnosing the needs of the market and customers is able to be more successful in the industry.

Specific teams of managers in the researcher will create research for the best solution to demands of the customers as a part of strategic implementation plan. A solution to issues above is the 'value' in the model above is the market value: the 'fair price' as perceived by customers. The approach for value innovation is business growth concentrating on new markets and strategic approach to business growth, involving a shift away from a focus on the existing competition to one of trying to create entirely new markets. Value innovation is achieved by implementing a focus on innovation and creation of new markets (Drucker, 1993).

This strategy gives to the organizations upon entering the market a competitive advantage, or be first advantage movers. This strategy allows not to focus on the differences among customers, but as value innovators looking for what customers' value in common. Rather than view opportunities through the lens of existing assets and capabilities, value innovators (Drucker, 1993).

Sustainable competitive strategy requires that organizations adopt a broad business view. It requires that organizations continuously pursue growth opportunities and innovative ways to improve existing products and services. Porter (2008) discussed the importance of successful organization adopting a mixed generic strategy of cost leadership, product differentiation and a focus strategy. Organizations successfully adopting and implementing a mixed generic strategy have the advantage to gain and maintain competitive advantage as competitors may be unable to duplicate approaches and strategies. As a part of the execution of the strategic plan, organizations should pursue a mixed generic strategy of leading the industry in providing cost effective products and services. The organizations will pursue this strategy by forming alliances with contractors, suppliers, and appliance manufactures to provide consumers added savings. 
ISSN 2661-264X (Print)

Successful organizations at implementation plan are aware of their need to fund their intended strategies and they begin to think about that necessary financial commitment early in the planning process. Annual business plan is an important tool to evaluate the success of the strategic plan. There is a reason why many organizations choose to follow an annual business performance; the unpleasant surprises that might arise during the budgeting time. To successfully implement your strategy, monitoring is an absolute necessity. Monitoring and controlling the plan includes a periodic look to see if you're on course. It also includes consideration of options to get a strategy once derailed back on track. The department managers must monitor the tactical plans, and the executive planning team must monitor the strategic plan. That way, if the strategy isn't happening, we can consider other options - changing the strategy, changing its implementation, or changing its due date.

\section{Recommendations}

Organizations today need to be better than their competition in competitive decision making, when analyzing strategic their options, consequently they will be a company that sets the tone for their industry then follow those leading. That is why implementing a plan of your strategy is important. To be an industry leader who sets the tone, and not a industry follower new and emerging business need to better understand those strategic options, and how important they are in the implementation process. The purpose of this research is to understand this process, analyzes and then creates a set of implementation plan to determine which business opportunities works best for international organizations, then justify those strategies. Implementing your strategic plan is as important, or even more important, than your strategy. A strategic plan provides a business with the roadmap it needs to pursue a specific strategic direction and set of performance goals, deliver customer value, and be successful. As a part of implementation plan, the researcher has identified the main issues of the strategy and has created solutions, which it will be executed in a time frame of one year. According to the results of the executing the strategic plan, organizations will evaluate the performance and take the necessary actions.

\section{References}

Birnbaum, B. (2011). Implementing your business strategy. Retrieved from http://www.birnbaumassociates.com/implementing-strategy.htm

Drucker, P., F. (1993).Innovation and entrepreneurship. New York: Harper Business, 30-36, 138,150

Kim. W., C., Mauborgne, R. (2004). Blue Ocean Strategy; Harvard Business Review (Boston: Harvard Business School Press): 76-85. 
ISSN 2661-2666( Online) International Scientific Journal “Monte” DOI : 10.33807/monte.3.201912503

ISSN 2661-264X (Print)

Metcalf, L. (2008). Counseling Towards salutations; San Francisco, CA: Wiley and Sons.

Porter, M., E. (2008). The five competitive forces that shape strategy. Harvard Business Review, 86(1), 78-93. 